\section{From the Editors-in-Chief}

\section{Mathew Bumbalough \& Adrienne Sewell}

The Journal of Academic Advising (JAA) is a peer-reviewed and open access publication that provides a forum for academic advisors and advising directors to publish and highlight their research in all facets of academic advising. We want to specifically say thank you for the work that our editorial team has put into making this issue a possibility, and for all of the submissions we received from our authors. Without them, this would not be possible.

We also valued the multidisciplinary approach that advisors brought to our inaugural issue. These approaches are enshrined in the JAA's mission to encourage interdisciplinary inquiry, methods, and theories in the field of academic advising; to promote the exchange of humanistic inquiry as it relates to advising; and, to facilitate collaboration between advising staff and faculty at higher education institutions.

The idea for this journal originated with a collaborative research group comprised of academic advisors here at Indiana University. Advising as a practice within settings of learning has historic roots dating to antiquity, was formalized in the mid $20^{\text {th }}$ century, and continues to evolve as an academic discipline today. As such, we felt the need for a forum where advisors could share what they were doing and how they perceived advising through the lens of their varied experiences, all the while adding to this rich tradition.

In this issue, we hoped to take the pulse of advising as a professional community and explore the issues with which advisors grapple-in both theory and practice-as they engage with their student populations. One can make the argument that advising is going through a liminal moment-a period of over- lap as the old gives way to the new. The profession of advising is transitioning from an administrative function to that of a discipline within higher education. With its own $\mathrm{PhD}$ program, several Masters programs, and graduate certificates in academic advising, the further formalization of our profession into a field of study will continue to give rise to the larger question of what it means to be an advisor in the $21^{\text {st }}$ century.

In this issue, we have chosen two articles that we believe best exemplify that liminality, articles that take from the advisors' practice, academic backgrounds, and deep thinking on advising in order to construct a new outlook on the future of best practices and theories in advising.

The first article, authored by Cheryl Wanko, examines advising as a sustainable practice, broadly defined as practicing a civic and social-minded responsibility in interactions with students. It problematizes the notion of educating for sustainability in the claim that higher education has itself too often been built upon unsustainable practices. As such, Wanko casts a vision that she names 'Advising for Sustainability', which suggests how advisors can build a sense of sustainability within their professional practice.

In this issue's second article, Kay Hamada makes use of the concept of disruptive innovation in an advising context. She argues this allows one to examine how trends in globalization, diversity, and communication are affecting the role of advisors in universities, and how we can adapt to those changes in a thoughtful and meaningful way.

As we continue our efforts at the Journal of Academic Advising, we hope that all readers of this journal will join us in a collective rumination on what it means to be an academic advisor on today's college campus. 